\title{
Long-term mental health of Vietnamese refugees in the aftermath of trauma
}

\author{
Aina Basilier Vaage, Per Hove Thomsen, Derrick Silove, Tore Wentzel-Larsen, Thong Van Ta
} and Edvard Hauff

\section{Background}

There is no long-term prospective study ( $>20$ years) of the mental health of any refugee group.

\section{Aims \\ To investigate the long-term course and predictors of psychological distress among Vietnamese refugees in Norway.}

\section{Method}

Eighty Vietnamese refugees, $57 \%$ of the original cohort previously interviewed in $1982\left(T_{1}\right)$ and $1985\left(T_{2}\right)$, completed a self-report questionnaire prior to a semi-structured interview. Mental health was measured using the Symptom Checklist-90-Revised (SCL-90-R)

\section{Results}

The SCL-90-R mean Global Severity Index (GSI) decreased significantly from $T_{1}$ to $T_{3}$ (2005-6), but there was no significant change in the percentage reaching threshold scores (GSI =1.00). Trauma-related mental disorder on arrival and the trajectory of symptoms over the first 3 years of resettlement predicted mental health after 23 years.

\section{Conclusions}

Although the self-reported psychological distress decreased significantly over time, a substantial higher proportion of the refugee group still remained reaching threshold scores after 23 years of resettlement compared with the Norwegian population. The data suggest that refugees reaching threshold scores on measures such as the SCL-90-R soon after arrival warrant comprehensive clinical assessment.

\section{Declaration of interest}

None.
To our knowledge no prospective longitudinal study has followed an adult refugee cohort for more than 10 years. We report findings from the third interview phase of a longitudinal prospective community cohort study of Vietnamese refugees settled in Norway. They were included in the study upon their arrival in Norway in $1982\left(T_{1}\right)$ and followed up in $1985\left(T_{2}\right) .{ }^{1}$ The earlier findings, of stable and high levels of mental health problems after 3 years in exile, ${ }^{2}$ are consistent with other subsequent short-term follow-up studies among refugees. ${ }^{3-5}$ The aims of the study reported here were to investigate the long-term course and outcome of these individuals' mental status, and to identify which early resettlement factors were relevant to predicting levels of psychological distress over 20 years later.

\section{Method}

\section{Design and procedures}

The design of the study was similar to that of the two earlier studies of this cohort. ${ }^{1}$ An interview administered in the respondents' home (by A.B.G. and A.B.V.) included a self-report questionnaire available in Vietnamese and Norwegian, and a structured face-to-face interview in Vietnamese. The study was approved by the regional committee for medical research ethics and the Norwegian Social Science Data Services. Written information about the study was provided in Vietnamese and Norwegian.

\section{Sample}

All Vietnamese refugees aged 15 years or older who arrived in south-east Norway from transit camps in south-east Asia during an 8-month period in 1982 were invited to take part in the first study $\left(T_{1}\right)$. Norwegian merchant vessels had rescued the refugees by chance from the South China Sea, and these people were offered resettlement in Norway. Thus the original cohort was a relatively unselected sample from this wave of Vietnamese 'boat people'. In the current study $\left(T_{3} ; 2005-6\right)$ we sought to interview all surviving members of the cohort remaining in Norway. We were able to collect data from 80 respondents; 24 others had died or moved to another country (Fig. 1). Hence the $T_{3}$ sample represented $57 \%$ of the original cohort and $74 \%$ of those eligible for inclusion.

The Norwegian normative sample, used for comparison of the Symptom Checklist-90-Revised (SCL-90-R) results, consisted of 466 men and 507 women over 19 years old who were representative of the adult population in Norway. ${ }^{6}$

\section{Assessments}

\section{Sociodemographic variables}

Included in the self-report questionnaire at $T_{3}$ were marital status, family reunion, presence of family in Norway, social network including Vietnamese and Norwegian friends, religious affiliation, level of education, current work status and economic support.

\section{Symptoms}

Psychological distress was rated with the same measure used in 1982 and 1985: the SCL-90-R. ${ }^{7}$ This instrument is considered valid and reliable, and has been used in several studies of refugee mental health, both in its original form, ${ }^{8,9}$ and as the shorter 25 -item Hopkins Symptom Checklist (HSCL-25). ${ }^{10,11}$ The Global Severity Index (GSI) represents the mean score of all 90 items of the SCL-90-R, with a score of 1 or more used to identify a probable psychiatric 'case. ${ }^{6}$ As self-report measures may be oversensitive in identifying true cases, ${ }^{12}$ we refer to those scoring at least 1 as reaching threshold score.

\section{Trauma exposure}

The analyses reported here included information gathered at $T_{1}$ and $T_{2}$. An additive index combining the factors of having been 


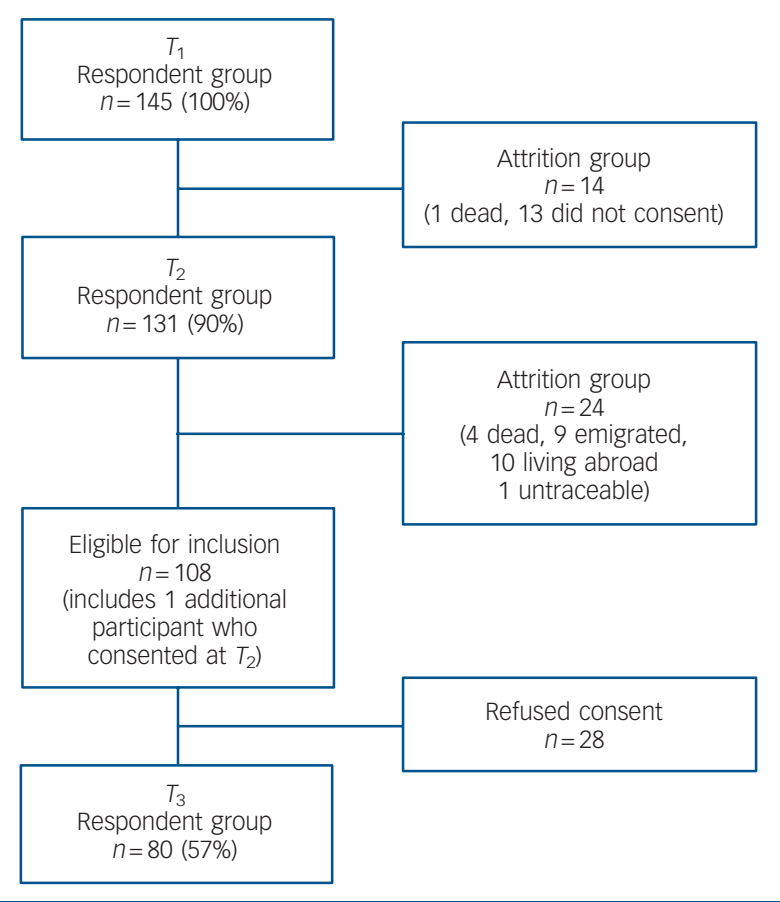

Fig. 1 Flow diagram of inclusion and attrition.

wounded in the war, having been incarcerated in prison or a concentration camp for a year or more, and having been in great danger before the escape represented the variable 'extreme traumatic stress' before the escape (minimum score 0 , maximum 3 ).

\section{Statistical analysis}

Univariate analyses included chi-squared tests, Mann-Whitney tests, $t$-tests and Pearson correlations. Changes in SCL-90-R scores over time were assessed by linear mixed effects models ( $\mathrm{R}$ version 2.9.7 for Windows, $\mathrm{R}$ package 'nlme', $\mathrm{R}$ Foundation for Statistical Computing, see www.r-project.org), ${ }^{13}$ adjusting for relevant $T_{1}$ variables. The relationships between SCL-90-R scores at $T_{3}$ and baseline $\left(T_{1} / T_{2}\right)$ variables were investigated by two types of multiple linear regression analyses. First, we generated a model identical to the one published for $T_{2}$ data, ${ }^{2}$ except that the outcome was the SCL-90-R GSI score at $T_{3}$ (independent variables measured at $T_{1}-$ or, if not assessed at $T_{1}$, at $T_{2}$ - were age, gender, years of education in Vietnam, an additive score of extreme traumatic stress, close confidante upon arrival, highimpact negative life events during the first 2 years in Norway, and separation from close family at $T_{2}$ ). Second, for a more comprehensive model predicting GSI at $T_{3}$, we included some pre-specified baseline variables from $T_{1}$ and $T_{2}$ together with two indices of mental health status prior to $T_{3}$, namely the GSI score at $T_{1}$ and a change measure (GSI at $T_{2}$ minus GSI at $T_{1}$, with a positive value indicating worsening of symptoms from $T_{1}$ to $T_{2}$ ). The significance level was set at 0.05 . When adjusting for multiple comparisons the Benjamini-Hochberg procedure was used. ${ }^{14}$ All analyses used SPSS version 15 for Windows and R (see above).

\section{Results}

\section{Sociodemographic variables}

The sample at $T_{3}$ consisted of 12 women and 68 men, with a mean age of 47.5 years (s.d. $=6.8$, range $38-70$ ), the respondent group being younger and comprising more men than women compared with the attrition group (further details are given in online Table DS1).

\section{Psychological distress}

All but one of the 80 respondents completed the SCL-90-R at $T_{3}$ (the exception was a person with psychosis). There was no significant gender difference in mean GSI scores at $T_{3}$ (women $0.48 v$. men 0.49 ). The mean GSI decreased significantly from 0.81 at $T_{1}$ to 0.49 at $T_{3}$ (difference: s.d. $=0.55,95 \%$ CI $0.29-0.44$, $P<0.001)$.

Table 1 shows the GSI mean scores at the three time points compared with the Norwegian normative sample (for subscale scores see online Table DS2). From arrival to follow-up at $T_{3}$ there were significant decreases in both the GSI and the means for all subscales of the SCL-90-R (online Table DS3), with the exception of somatisation and anger/hostility. Eighteen per cent of respondents $(n=14)$ reached threshold scores at $T_{3}$ $(\mathrm{GSI}=1.00)$, more than twice the percentage of Norwegians (7.2\%). For the Vietnamese cohort there was no significant difference between GSI rates at $T_{3}$ and those recorded at $T_{2}$ $(25 \%, n=20)$ and $T_{1}(26 \%, n=20)$.

\section{Prediction of psychological distress at $T_{3}$}

In the first regression analysis using $T_{1} / T_{2}$ predictors and GSI at $T_{3}$, the model being similar to the one published earlier, ${ }^{2}$ the included predictors explained $13 \%$ of the variance of GSI but no single predictor was associated significantly with the index of distress at $T_{3}$. In the second regression, a greater GSI score at $T_{1}$ and the change score (the difference in GSI scores between $T_{2}$ and $T_{1}$ ) were both significant predictors of a higher GSI at $T_{3}$ (Table 2).

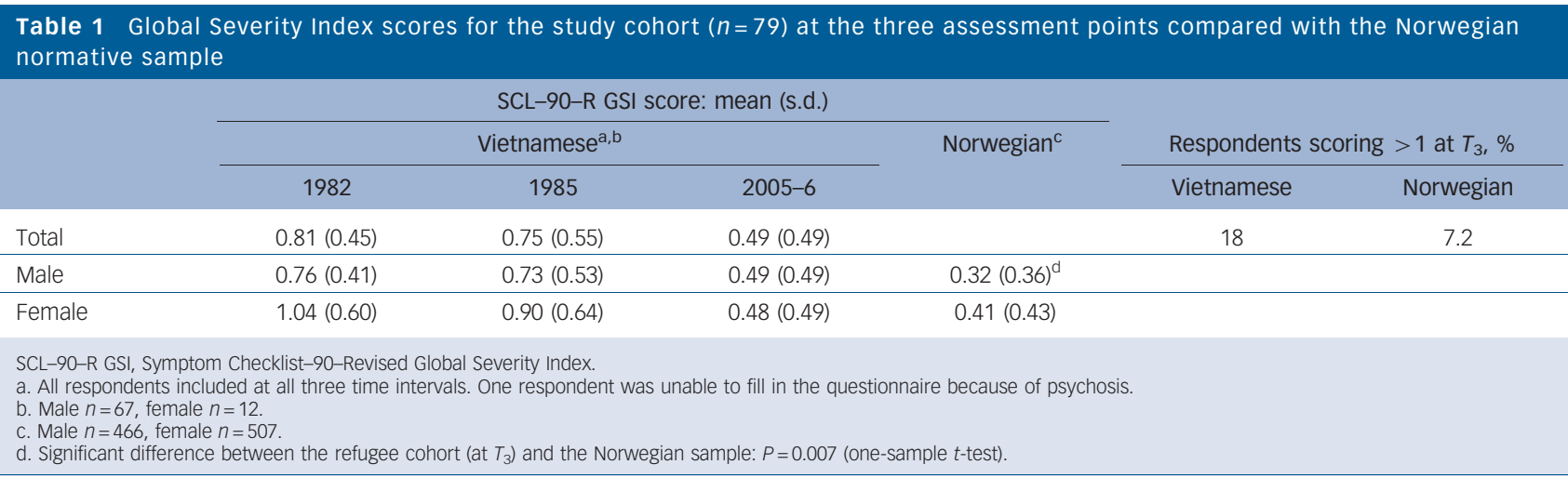


Table 2 Multiple regression analysis for Global Severity Index scores at $T_{3}(n=79)$

\begin{tabular}{|c|c|c|c|c|}
\hline Variables from $T_{1} / T_{2}$ & Regression coefficient & $P$ & $95 \% \mathrm{Cl}$ & $R^{2}$ \\
\hline Age at inclusion & -0.001 & 0.86 & -0.02 to 0.01 & 0.008 \\
\hline Gender $^{\mathrm{a}}$ & 0.11 & 0.44 & -0.18 to 0.40 & 0.009 \\
\hline Vietnamese contact $^{b}$ & 0.14 & 0.19 & -0.07 to 0.34 & 0.049 \\
\hline Norwegian contact $^{\mathrm{C}}$ & 0.09 & 0.54 & -0.20 to 0.37 & 0.062 \\
\hline Health $^{d}$ & -0.003 & 0.98 & -0.23 to 0.22 & 0.10 \\
\hline GSI score at $T_{1}$ & 0.48 & $<0.001$ & 0.23 to 0.73 & 0.16 \\
\hline GSI difference $\left(T_{2}-T_{1}\right)^{e}$ & 0.41 & 0.001 & 0.19 to 0.63 & 0.31 \\
\hline \multicolumn{5}{|c|}{$\begin{array}{l}\text { GSI, Global Severity Index; } T_{1} \text {, 1982; } T_{2}, 1985 ; T_{3} \text {, 2005-6. } \\
\text { a. Gender: female } 1 \text {, male } 2 \text { (reference category 'female'). } \\
\text { b. Extent of Vietnamese contact at } T_{2} \text { : adequate } 0 \text {, inadequate } 1 \text { (reference category 'adequate contact'). } \\
\text { c. Extent of Norwegian social contact at } T_{2} \text { : adequate } 0 \text {, inadequate } 1 \text { (reference category 'adequate contact'). } \\
\text { d. Present self-reported health at } T_{2}: \text { good health } 1 \text {, other } 2 \text { (reference category 'good health'). } \\
\text { e. Difference in GSI score between } T_{2} \text { and } T_{1} \text {. }\end{array}$} \\
\hline
\end{tabular}

\section{Discussion}

Our results suggest a complex picture. The mental health of the cohort as a whole had improved significantly since the refugees' arrival in Norway, but the mean scores on the SCL-90-R remained higher than for native Norwegians. Almost a fifth of the cohort, more than twice the percentage of Norwegians had psychological distress scores above threshold on the SCL-90-R, suggesting that the Vietnamese remained a vulnerable group. These findings are broadly consistent with those of Steel et al in suggesting that the majority of Vietnamese had achieved reductions in most symptom domains over time, but a minority remained highly symptomatic. ${ }^{15}$

\section{Implications for the treatment of refugees}

Our findings may help to clarify the trajectory of symptoms among refugees over a prolonged period of resettlement. In stable resettlement environments, refugee populations tend to manifest high levels of distress over the earlier years, as indicated by the results for $T_{1}$ and $T_{2}$. This is consistent with other studies, ${ }^{4}$ and supports the notion that a combination of recent trauma and resettlement/acculturation challenges continue to act as stressors during this time. Nevertheless, the $T_{3}$ data indicate that at a population level, and in the context of a stable resettlement environment, ${ }^{16,17}$ most refugees have the capacity for symptom improvement over the longer term, although levels of distress may remain higher than among the host population. Symptom improvement during the first 3 years, signified in this study by a reduction in GSI between $T_{1}$ and $T_{2}$, may therefore represent an important predictor of a positive long-term prognosis, in this instance after 23 years.

\section{Prediction of outcomes: implications for early assessment and intervention}

A minority of study participants remained psychologically impaired over many years. Trauma might have been a factor initiating some of these reactions, but in the longer term, as indicated, a key predictive index appeared to be the level and trajectory of psychological symptoms during the period of early resettlement. This supports the potential value of serial screening programmes for refugees, a procedure that could be followed by comprehensive assessment of the identified at-risk group to detect those with clinical disorders in need of treatment. Hence, early intervention may be relevant not only to overcome immediate distress but also to avert risk of psychological difficulties in later years. Still, the predictive capacity of the regression analysis was modest, suggesting that other unmeasured post-migration experiences and/or personal vulnerabilities might have a role in perpetuating psychological symptoms over time, ${ }^{18}$ or in initiating new disorders during the ensuing two decades.

\section{Limitations}

Despite of the strengths of the study, in particular its prospective longitudinal design, important limitations need consideration. Attrition is evident in most refugee studies, ${ }^{4}$ and compared with the attrition group, included respondents were younger and more often male than female. This, together with the small original sample and the special characteristics of Norwegian society, may limit the generalisability of the findings to other refugee populations. In addition, gender-specific comparisons could not be undertaken because the relevant information was not available for the Norwegian normative data-set.

The follow-up study did not include a clinical diagnostic interview, which limits comparisons with other studies of refugees. ${ }^{19,20}$ Although a study among Vietnamese refugees has shown reasonable concordance between a clinical interview (the Structured Clinical Interview for DSM-IV Axis I disorders) and the HSCL-25, ${ }^{21}$ a comparable study among Cambodians indicated that a clinical interview yielded a more conservative prevalence rate. ${ }^{12} \mathrm{~A}$ recent meta-analysis of the entire refugee mental health field showed a regular pattern in which questionnaires (often derived from the Symptom Checklist) on average returned a $10-13 \%$ higher prevalence than interviews when other methodological factors (sample size, approach to sampling) were taken into account. ${ }^{22}$ These observations caution against inferring that all Vietnamese who scored above threshold in our study could definitely be assigned to the 'cases' group. Further examination would be needed (and warranted) to specify accurately those in need of treatment.

We acknowledge the risk of reduced semantic equivalence arising from the use of an early version of the Vietnamese translation of the SCL-90-R, ${ }^{23}$ but we considered it important to use the same translation for longitudinal comparisons. Other studies among Vietnamese have used a culturally specific measure of mental health, the Phan Vietnamese Psychiatric Scale (PVPS), in conjunction with an international instrument. ${ }^{24}$ This approach increased the overall rates of detected mental health disorders, suggesting the possibility that cases may be overlooked when Western-derived instruments such as the SCL-90-R are used alone.

\section{Clinical implications}

Although self-reported psychological distress among Vietnamese refugees decreased significantly over time, even after 23 years of 
resettlement a greater proportion of this cohort reached threshold SCL-90-R scores compared with the native Norwegian group. Therefore, this population should still be considered to be at increased risk of mental health problems, justifying special attention from psychiatric services. The longitudinal data support the importance of screening refugees in the early years of resettlement, since elevated levels of psychiatric symptoms during that period appear to indicate long-term risk.

Aina Basilier Vaage, MD, Centre for Child and Adolescent Mental Health, University of Bergen, and Department of Child and Adolescent Psychiatry, Stavanger University Hospital, Stavanger, Norway; Per Hove Thomsen, MD, PhD, Centre for Child and Hospital, Stavanger, Norway; Per Hove Thomsen, MD, PhD, Centre for Child and
Adolescent Psychiatry, University of Aarhus, Denmark, and Centre for Child and Adolescent Mental Health, University of Bergen, Norway; Derrick Silove, FRANZCP. MD, Psychiatry Research and Teaching Unit, School of Psychiatry, University of New South Wales, and Centre for Population Mental Health Research, Sydney South West Area Health Service, Sydney, New South Wales, Australia; Tore Wentzel-Larsen MSc, Centre for Clinical Research, Haukeland University Hospital, Bergen, Norway; Thong Van Ta, International House Foundation, Stavanger, Norway; Edvard Hauff MD, PhD, Institute of Psychiatry, University of Oslo, and Oslo University Hospital, Ullevål Department of Psychiatry, Oslo, Norway

Correspondence: Dr Aina Basilier Vaage, BUPA, SUS, Box 8100, 4068 Stavanger Norway. Email: aina.b.vaage@lyse.net

First received 14 Oct 2008, final revision 1 Sep 2009, accepted 25 Sep 2009

\section{Funding}

The study was supported by grants from the Western Norway Regional Health Authority the Centre for Child and Adolescent Mental Health, University of Bergen, the Legacy of Sommer, Lundbeck Pharma AS, the Meltzers Høyskolefond, Stavanger University Hospital and Oslo University Hospital, Ullevål Department of Psychiatry.

\section{References}

1 Hauff E. The stresses of war, organised violence and exile: a prospective community cohort study of the mental health of Vietnamese refugees in Norway [dissertation]. Instituttgruppe fur medisinke basalfag, University of Oslo, 1998.

2 Hauff E, Vaglum P. Organised violence and the stress of exile. Predictors of mental health in a community cohort of vietnamese refugees three years after resettlement. Br J Psychiatry 1995; 166: 360-7.

3 Mollica RF, Caridad KR, Massagli MP. Longitudinal study of posttraumatic stress disorder, depression, and changes in traumatic memories over time in Bosnian refugees. J Nerv Ment Dis 2007; 195: 572-9.

4 Lie B. A 3-year follow-up study of psychosocial functioning and general symptoms in settled refugees. Acta Psychiatr Scand 2002; 106: 415-25.

5 Silove D, Ekblad S. How well do refugees adapt after resettlement in Western countries? Acta Psychiatr Scand 2002; 106: 401-2.

6 Vassend O, Lian L, Andersen HT. Norske versjoner av NEO-Personality Inventory, Symptom Checklist 90 Revised og Giessen Subjective Complaints List. Del I. Tidsskr Nor Psykologforen 1992; 29: 1150-60.
7 Derogatis LR. SCL-90-R Administration, Scoring and Procedures Manual-I for the (Revised) Version. Johns Hopkins School of Medicine, 1977.

8 Ghazinour M, Richter J, Eisemann M. Quality of life among Iranian refugees resettled in Sweden. J Immigr Health 2004; 6: 71-81.

9 Araya M, Chotai J, Komproe IH, de Jong JTVM. Effect of trauma on quality of life as mediated by mental distress and moderated by coping and socia support among postconflict displaced Ethiopians. Qual Life Res 2007; 16 915-27.

10 Thapa SB, Hauff E. Psychological distress among displaced persons during an armed conflict in Nepal. Soc Psychiatry Psychiatr Epidemiol 2005; 40: 672-9.

11 Hermansson AC. The mental health of war-wounded refugees: an 8-year follow-up. J Nerv Ment Dis 2002; 190: 374-80.

12 Silove D, Manicavasagar V, Mollica R, Thai M, Khiek D, Lavelle J, et al. Screening for depression and PTSD in a Cambodian population unaffected by war: comparing the Hopkins Symptom Checklist and Harvard Trauma Questionnaire with the structured clinical interview. J Nerv Ment Dis 2007; 195: 152-7.

13 Pinheiro JC, Bates DM. Mixed Effects Models in S and S-plus. Springer, 2000.

14 Benjamini $Y$, Hochberg $Y$. Controlling the false discovery rate: a practical and powerful approach to multiple testing. J R Stat Soc Ser B 1995; 57: 289-330.

15 Steel Z, Silove D, Phan T, Bauman A. Long-term effect of psychological trauma on the mental health of Vietnamese refugees resettled in Australia: a population-based study. Lancet 2002; 360: 1056-62.

16 Schweitzer R, Melville F, Steel Z, Lacherez P. Trauma, post-migration living difficulties, and social support as predictors of psychological adjustment in resettled Sudanese refugees. Aust N Z J Psychiatry 2006; 40: 179-87.

17 Porter M, Haslam N. Predisplacement and postdisplacement factors associated with mental health of refugees and internally displaced persons: a meta-analysis. JAMA 2005; 294: 602-12.

18 Marshall GN, Schell TL, Elliott MN, Berthold SM, Chun CA. Mental health of Cambodian refugees 2 decades after resettlement in the United States. JAMA 2005; 294: 571-9.

19 Roth G, Ekblad S, Agren H. A longitudinal study of PTSD in a sample of adult mass-evacuated Kosovars, some of whom returned to their home country. Eur Psychiatry 2006; 21: 152-9.

20 Hinton D, Chau H, Nguyen L, Nguyen M, Pham T, Quinn S, et al. Panic disorder among Vietnamese refugees attending a psychiatric clinic: prevalence and subtypes. Gen Hosp Psychiatry 2001; 23: 337-44.

21 Smith Fawzi MC, Murphy E, Pham T, Lin L, Poole C, Mollica RF. The validity of screening for post-traumatic stress disorder and major depression among Vietnamese former political prisoners. Acta Psychiatr Scand 1997; 95: 87-93.

22 Steel Z, Chey T, Silove D, Marnane C, Bryant RA, van Ommeren M. Association of torture and other potentially traumatic events with mental health outcomes among populations exposed to mass conflict and displacement: a systematic review and meta-analysis. JAMA 2009; 302: $537-49$.

23 Flaherty JA, Gaviria MF, Pathak D, Mitchell T, Wintrob R, Richman J, et al. Developing instruments for cross-cultural psychiatric research. J Nerv Ment Dis 1988; 176: 257-63.

24 Phan T, Steel Z, Silove D. An ethnographically derived measure of anxiety, depression and somatization: the Phan Vietnamese Psychiatric Scale. Transcult Psychiatry 2004; 41: 200-32. 